\title{
The effects of visual feedback during a rhythmic weight-shifting task in patients with Parkinson's disease
}

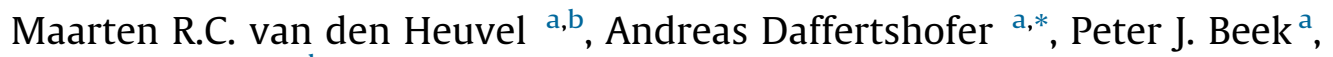 \\ Gert Kwakkel $^{\mathrm{a}, \mathrm{c}, \mathrm{d}}$, Erwin E.H. van Wegen ${ }^{\mathrm{a}, \mathrm{c}}$ \\ ${ }^{a}$ Department of Human Movement Sciences, Faculty of Behaviour and Movement Sciences, Vrije Universiteit Amsterdam, MOVE Research Institute \\ Amsterdam, van der Boechorststraat 9, 1081 BT Amsterdam, The Netherlands \\ ${ }^{\mathrm{b}}$ Department of Motion Science, Westfälische Wilhelms-Universität Münster, Horstmarer Landweg 62b, D-48149 Münster, Germany \\ ${ }^{\mathrm{c}}$ Department of Rehabilitation Medicine, VU University Medical Center, MOVE Research Institute Amsterdam, De Boelelaan 1118, 1007 MB Amsterdam, \\ The Netherlands \\ ${ }^{\mathrm{d}}$ Department of Neurorehabilitation, Reade Center for Rehabilitation and Rheumatology, Overtoom 283, Amsterdam, The Netherlands
}

\section{A R T I C L E I N F O}

\section{Article history:}

Received 21 October 2015

Received in revised form 16 February 2016

Accepted 31 March 2016

\section{Keywords:}

Postural control

Parkinson's disease

Visual feedback

Time delay

Center-of-pressure

\begin{abstract}
A B S T R A C T
Augmented visual feedback (VF) may offer benefits similar to those of rhythmic external cues in alleviating some mobility-related difficulties in individuals with Parkinson's disease (PD). However, due to an impaired ability to reweigh sensory information under changing circumstances, subjects with PD may be rather vulnerable to incongruity of visual information. In the present study, we investigated whether VF is indeed effective in improving motor functioning in a weight-shifting task during upright stance, and whether subjects with PD are affected more by incongruent VF than healthy controls. Participants performed sideways swaying motions based on tracking of real-time and delayed VF - the first providing congruent, and hence more accurate, visual information than the latter. We analyzed center-of-pressure signals patterns for 28 individuals with PD and 16 healthy, age- and gender-matched controls by estimating task accuracy, movement pattern variability, and normalized movement amplitude. For conditions without feedback and with real-time feedback, subjects with PD performed lateral swaying motions with greater error $(F(1,42)=12.065, p=.001)$ and with more variable movement patterns than healthy controls $(F(1,24)=113.086, p<.001)$. Error change scores revealed that patients with PD were nevertheless still able to use VF to improve tracking performance $(t(24)=-2.366, p=.026)$. However, whereas controls were able to adapt to a certain amount of visual incongruity, patients with PD were not. Instead, movement amplitude was significantly reduced in this group $(F(1.448,60.820)=17.639, p<.001)$. By reducing movement amplitude, subjects with PD appear to resort to a 'conservative' strategy to minimize performance breakdown.
\end{abstract}

(c) 2016 Elsevier B.V. All rights reserved.

\section{Introduction}

Parkinson's disease (PD) is a progressive neurodegenerative disorder, in which extensive degeneration of dopaminergic neurons in the substantia nigra gives rise to significant motor and non-motor symptoms [1]. Cardinal motor symptoms are bradykinesia, tremor, rigidity, and loss of postural reflexes [1]. As the disorder progresses, deterioration of the patient's functional motor capacity may lead to various problems with balance,

\footnotetext{
* Corresponding author. Tel.: +31 0205988468 .

E-mail addresses: m.r.c.vanden.heuvel@vu.nl (Maarten R.C. van den Heuvel), a.daffertshofer@vu.nl (A. Daffertshofer), p.j.beek@vu.nl (P.J. Beek), g.kwakkel@vumc.nl (G. Kwakkel), e.vanwegen@vumc.nl (Erwin E.H. van Wegen).
}

transfers, and walking. 'Transfers' refer to a range of activities that require a shift of the body's center-of-mass [2]. For instance, taking a step requires one to first unload the swing limb by laterally shifting weight to the stance leg. Subjects with PD-related postural instability show smaller and slower lateral center-of-pressure (COP) displacements during weight transfer from one leg to the other [3,4]. It is unclear, however, how dopamine deficiency mediates these motor impairments. Mobility-related difficulties in PD can be improved when the subjects are given external, rhythmic, movement-related auditory, somatosensory, or visual stimuli [5-7]. Augmented visual feedback (VF) may increase the beneficial effects of cueing by adding kinematic performance to the visual scene. While this may potentially be a useful avenue for promoting motor behavior and learning, several studies have demonstrated that subjects with PD have an impaired ability to 
properly reweigh sensory information under changing circumstances (e.g., $[8,9])$. As a consequence, these subjects may be more vulnerable to information that is inaccurate or otherwise impaired, for they might find it difficult to adapt appropriately. In the present study our interest was twofold: first, we asked whether VF is effective in improving motor performance in a weight-shifting task; second, we asked whether incongruent and thus inaccurate VF affects motor performance more in subjects with PD than in healthy controls.

In general, the dependence on visual information can be assessed by examining subjects' performance under visual tracking conditions in which relying on VF becomes unfavorable. Besides withdrawing visual information altogether, one may realize this by introducing a delay in the feedback loop [10-12]. If $\mathrm{VF}$ is delayed by at least a few tenths of a second, maintaining task performance becomes very difficult. Note that a delay preserves the overall visual input of the VF. To deal with a delay one may (1) adapt the sensorimotor loop in order to account for the delay or (2) try to dissociate performance and feedback, and only intermittently use the feedback to obtain an impression of the performance [13].

Our primary objective was to investigate instantaneous effects of $\mathrm{VF}$ during a visual tracking task involving lateral displacements of the center-of-mass while standing. Weight-shifting task performance of a PD group was compared with that of a group of healthy, age- and gender-matched controls. The second objective was to investigate whether subjects with PD are affected more by delayed VF than healthy controls. Task performance was characterized using measures reflecting accuracy, movement pattern variability, and movement amplitude.

We hypothesized that subjects with PD would perform the lateral weight-shifting task less accurately than healthy controls, as evidenced by an increased tracking error, and that both groups would benefit from the availability of visual feedback. We further hypothesized subjects with PD to be less successful in adapting to unreliable (here delayed, i.e. incongruent) VF than healthy controls.

\section{Methods}

\subsection{Design}

We performed a cross-sectional study of standing balance performance in a PD group and a group of age- and gendermatched healthy controls. The patient data considered in this report were derived from baseline assessments that were performed as part of a randomized clinical trial (RCT), registration number ISRCTN47046299 [14]. The protocol was approved by the Medical Ethics Committee of VU University Medical Center (VUmc) Amsterdam. All participants signed informed consent. Results from the RCT were reported elsewhere [15].

\subsection{Participants}

Subjects with PD were recruited from databases of the Department of Rehabilitation Medicine of VUmc. Inclusion criteria were (i) a diagnosis of idiopathic PD according to the UK Brain Bank criteria [16], mild to moderate stage (i.e. Hoehn and Yahr stages II and III), (ii) able to participate in either of the training programs, and (iii) written and verbal informed consent. Exclusion criteria were: (i) presence of (other) neurological, orthopedic, or cardiopulmonary problems that could impair participation, (ii) Mini Mental State Examination (MMSE) score below 24 points, (iii) a recent change in dopaminergic medication, and (iv) cognitive, visual, and/or language problems impeding participation. Patients underwent the assessment in the ON-phase of levodopa medication, approximately $1.5 \mathrm{~h}$ after intake of the last medication dosage. The controls were recruited by asking all participating patients to inquire in their social environment whether a partner or friend would be willing to serve as a control subject.

\subsection{Assessments}

Functional standing balance outcomes included the functional reach test (FRT) [17], the Berg Balance Scale (BBS) [18], the single leg stance test (SLS), and the 10-m walk test [19]. Posturographic assessments were based on movement accuracy, movement pattern variability, and amplitude. In the weight-shifting task, participants tracked a visual target by making lateral displacements of the center-of-mass. Performance was characterized by tracking error (Error), movement pattern variability $\left(\operatorname{Var}_{c}\right)$, and (normalized) movement amplitude ( $A_{\text {norm }}$; see Data analysis).

Sex, age, and fall status were documented. Subjects were categorized as a faller if they reported to have fallen in the 6 months prior to assessment. All participants completed the Falls Efficacy Scale (FES), which assesses balance confidence [20], the Hospital Anxiety and Depression Scale (HADS) [21], and the Multidimensional Fatigue Inventory (MFI) $[22,23]$.

For the patients, disease duration, medication intake, Hoehn and Yahr stage (HY), score on the Unified Parkinson Disease Rating Scale (UPDRS), and the Parkinson's Disease Questionnaire-39 (PDQ-39) [24] were documented.

\subsection{Rhythmic weight-shifting task with VF}

Subjects stood upright on a $600 \mathrm{~mm} \times 400 \mathrm{~mm}$ force plate (Kistler 9281B, Ostfildern, Germany), facing a 15-in. LCD monitor at eye-height about $80 \mathrm{~cm}$ away. Each trial consisted of three sections, which appeared in the following sequence: $20 \mathrm{~s}$ quiet stance, $100 \mathrm{~s}$ of voluntary rhythmic swaying in the frontal plane (i.e. sideways), and 20 s quiet stance (Fig. 1). Data were sampled at a rate of $1 \mathrm{kHz}$. During quiet stance, subjects were asked to take a neutral position and stand still while focusing on a fixed black circle. During rhythmic lateral swaying the black circle moved horizontally on the monitor according to a sinusoidal function with a frequency of $0.5 \mathrm{~Hz}$. Subjects were asked to track the target's motion by swaying their whole body in the frontal plane at a comfortable tempo. During this task a red dot indicated motions of the subject's COP. COP feedback was limited to motions along the mediolateral axis only. An online low-pass filter with a cut-off frequency of $25 \mathrm{~Hz}$ was implemented to smooth the feedback signal. We presented feedback either in real time, or delayed by 250 or $500 \mathrm{~ms}$ (referred to below as $\mathrm{VF}_{\mathrm{rt}}, \mathrm{VF}_{250}$, and $\mathrm{VF}_{500}$ ), respectively. In the control condition, only the target signal was visible $\left(V_{\text {no, }}\right.$, see Fig. 1$)$ and the subjects were asked to sway comfortably, matching the motion of the target.

For each subject the average peak excursion during familiarization with $\mathrm{VF}_{\mathrm{no}}$ was used as the target signal's amplitude throughout the actual protocol. Subjects familiarized themselves with the adjusted target amplitude under real-time VF, until they indicated they felt comfortable to perform the task. Each condition was repeated three times, with repetitions presented in randomized blocks. Between trials subjects were asked to step off the force plate and to take rest if desired.

\subsection{Data analysis}

For the functional standing balance tests, the assessments of mobility-related anxiety and fatigue, and the disease-specific questionnaires, the mean (sub)scores were computed according to each test's guidelines [25]. All posturographic analyses were conducted in Matlab R2014 (The Mathworks, Natick, MA). Subjects 


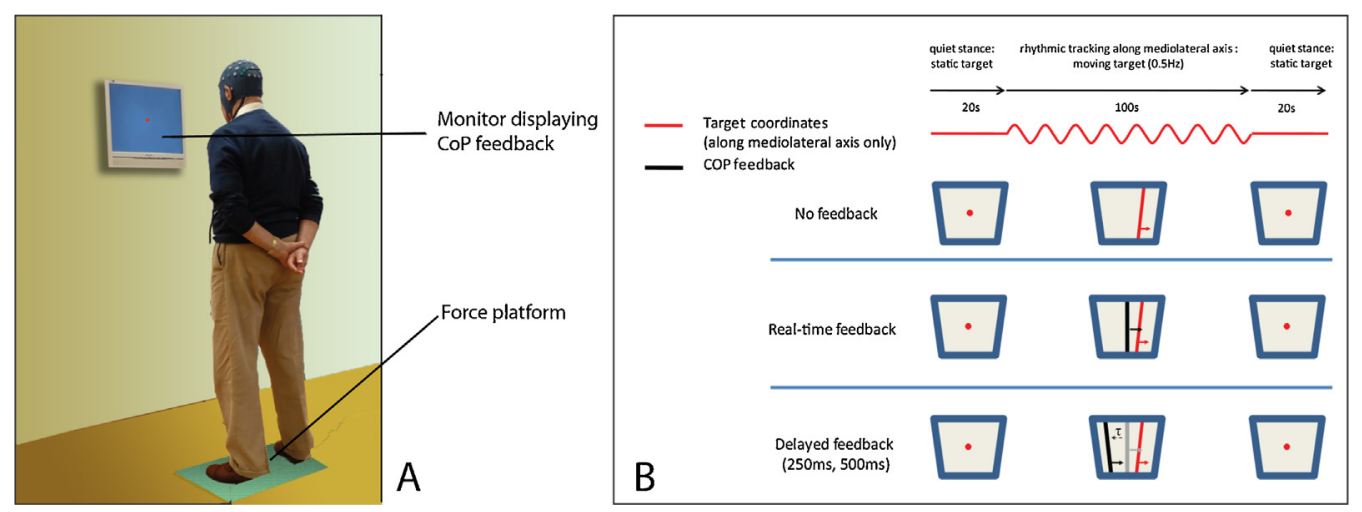

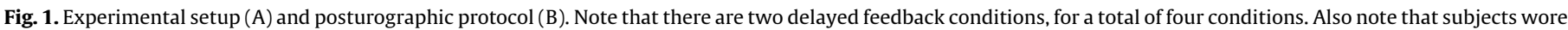
a headcap for EEG recordings, results of which are not reported here.

Adapted from [14].

who carried out at least two repetitions for each condition were included in the analysis.

We restricted analysis to COP movements along the ML axis. Raw COP and target time series were normalized by the target amplitude (which varied between subjects, see Protocol). Per trial, tracking error (Error) was determined by taking the mean absolute difference between the normalized COP and target. As a measure of tracking variability the circular variance $\left(\operatorname{Var}_{c}\right)$ of the relative phase was determined. Phases of COP and target time series were obtained via the corresponding analytic signals computed using the Hilbert transform. The relative phase between the two phase time series was obtained by subtracting the target's phase from the COP phase, and $\operatorname{Var}_{c}$ was subsequently computed for every trial [26]. Var $_{c}$ is indicative of the divergence of relative phase over time: it is zero if the COP and target signal maintain a stable, unimodal phase relation, and will tend to 1 with increasingly dispersed phase relations $\left(\operatorname{Var}_{c}=1\right.$ implies a uniformly distributed relative phase). Normalized amplitude $\left(A_{\text {norm }}\right)$ was computed as the average peak excursion of the COP (in both left and right direction) during each trial, normalized with respect to the amplitude of preference during $\mathrm{VF}_{\text {no. }}$. For each outcome measure, and for each condition, we also computed the change over the course of the assessment. Thereto the difference in outcome between the first one-third of the first trial and the last one-third of the last trial was computed.

Prior to statistical analysis a Fisher $z$-transform was applied to $\operatorname{Var}_{c}$, and a log-transformation to Error, to stabilize normality.

\subsection{Statistical analysis}

All outcomes were analyzed using IBM SPSS Statistics 21. Outcomes were tested for departures from normality using the Shapiro-Wilk test. All balance and gait related descriptors and outcomes were tested for group differences by means of an independent samples $t$-test, or a nonparametric Mann-Whitney $U$ test if the assumptions for parametric testing were not met. A Chi-square test served to test differences between groups in the proportions of male and females, and fallers and non-fallers. All tests were two-tailed $(\alpha=0.05)$. We evaluated posturographic data by the following Mixed ANOVAs:

- Hypothesis 1: group $\times$ feedback. To examine group differences in performance with and without feedback, VFno and VFrt were used as within-subjects factors.

- Hypothesis 2: group $\times$ delay. To examine group differences in the effect of incongruent VF, VFrt, VF250, and VF500 were used as within-subjects factors.
All change scores were tested by means of multiple one-sample $t$-tests. In the case of outliers we calculated the $5 \%$-trimmed mean, which is the mean after discarding the lowest and highest $5 \%$ of the observations. This provides a robust estimate of the central tendency of the data. If Mauchly's test of sphericity was significant, a Huynh-Feldt correction was used. Partial eta-squared $\left(\eta_{p}^{2}\right)$ is reported as a measure of effect size.

\section{Results}

Data were collected for 31 subjects with PD and 16 healthy controls (see flowchart in supplementary material). Three subjects with PD were excluded from analysis: one could not complete the experiment due to fatigue, and two others had difficulty performing the task. During the experiment none of the participants fell.

As shown in Table S1, the groups did not differ significantly in mean age (PD: $67.04 \pm 8.29$ yrs, control: $67.25 \pm 6.72$ yrs; $p=.930$ ), in the proportion of males to females (PD: 17/11, control: 8/8; $p=.540$ ) and in the proportion of fallers to non-fallers (PD: $12 / 16$, control: $3 / 13 ; p=.185$ ). Mean duration since diagnosis of PD was 9.86 $( \pm 7.42)$ years, with a median total UPDRS score of 49 (interquartile range: 32-63), and with the majority of patients in HY stage 2.5 .

\subsection{Functional standing balance}

Distance reached on the FRT was significantly shorter for patients with PD (mean difference of $4.23 \mathrm{~cm}, p=.048$ ). The patient group scored 3.0 points lower on the BBS $(p=.001)$. Stance duration during SLS was lower for the PD group, with a significant median difference for the non-preferred leg (22.98 s, $p=.026)$, but not for the preferred leg (22.90 s, $p=.079$ ). The PD group walked on average $0.18 \mathrm{~m} / \mathrm{s}$ slower during the $10-\mathrm{m}$ walk test $(p=.036)$, but step length did not differ significantly $(p=0.215)$.

\subsection{Posturography}

Hypothesis 1. Effects of augmented feedback

Typical COP signals can be found in the supplementary materials; summary statistics in Table 1 . No significant group $\times$ feedback interaction effect was found for the outcome Error ( $p=.181$, see Fig. $2 \mathrm{~A}$ ). There was a significant main effect of group, indicating greater Error for PD patients than for controls $(p=.001)$, as well as a significant main effect of feedback $(p=.023)$, indicating higher Error for the condition with feedback. 
Table 1

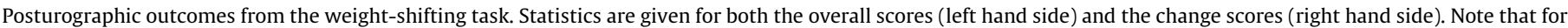

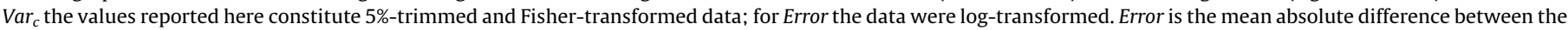

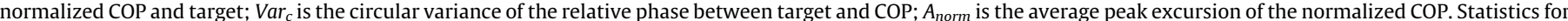

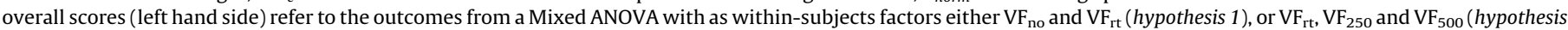
2). Partial eta-squared $\left(\eta_{p}^{2}\right)$ is reported as a measure of effect size. Statistics for change scores (right hand side) refer to the outcomes from one-sample $t$-tests.

\begin{tabular}{|c|c|c|c|c|c|c|c|c|c|c|c|c|c|c|c|c|c|}
\hline & \multicolumn{11}{|c|}{ Overall scores } & \multicolumn{6}{|c|}{ Change scores } \\
\hline & PD & Controls & statistics & & & & & & & & & PD & & & Controls & & \\
\hline & mean $\pm \mathrm{sd}$ & mean $\pm \mathrm{sd}$ & interaction & $p$ & $\eta_{p}{ }^{2}$ & group & $p$ & $\eta_{p}^{2}$ & feedback & $p$ & $\eta_{p}^{2}$ & mean $\pm \mathrm{sd}$ & $t$ & $p$ & mean \pm sd & $t$ & $p$ \\
\hline \multicolumn{18}{|l|}{ Error } \\
\hline $\mathrm{VF}_{\mathrm{no}}$ & $-0.45 \pm 0.16$ & $-0.65 \pm 0.12$ & \multirow{2}{*}{$\begin{array}{r}F(1,42) \\
=1.85\end{array}$} & \multirow{2}{*}{.181} & \multirow{2}{*}{.042} & \multirow{2}{*}{$\begin{array}{l}F(1,42) \\
=12.07\end{array}$} & \multirow{2}{*}{.001} & \multirow{2}{*}{.223} & \multirow{2}{*}{$\begin{array}{r}F(1,42) \\
=5.53\end{array}$} & \multirow{2}{*}{.023} & \multirow{2}{*}{.116} & $0.01 \pm 0.03$ & 0.320 & 0.752 & $-0.05 \pm 0.02$ & -2.457 & 0.028 \\
\hline $\mathrm{VF}_{\mathrm{rt}}$ & $-0.43 \pm 0.20$ & $-0.57 \pm 0.17$ & & & & & & & & & & $-0.08 \pm 0.04$ & -2.366 & 0.026 & $-0.12 \pm 0.03$ & -2.966 & 0.010 \\
\hline $\mathrm{VF}_{250}$ & $-0.22 \pm 0.16$ & $-0.26 \pm 0.15$ & \multirow{2}{*}{$\begin{array}{l}F(1.62,68.15) \\
=6.23\end{array}$} & \multirow[t]{2}{*}{.006} & \multirow[t]{2}{*}{.129} & \multirow{2}{*}{$\begin{array}{l}F(1,42) \\
=1.76\end{array}$} & \multirow[t]{2}{*}{.192} & \multirow[t]{2}{*}{.040} & \multirow{2}{*}{$\begin{array}{l}F(1.62,68.15) \\
=161.55\end{array}$} & \multirow[t]{2}{*}{$<.001$} & \multirow[t]{2}{*}{.794} & $-0.08 \pm 0.04$ & -2.397 & 0.024 & $-0.19 \pm 0.05$ & -3.756 & 0.002 \\
\hline $\mathrm{VF}_{500}$ & $-0.10 \pm 0.08$ & $-0.07 \pm 0.06$ & & & & & & & & & & $-0.07 \pm 0.03$ & -2.735 & 0.012 & $0.08 \pm 0.03$ & 2.058 & 0.059 \\
\hline \multicolumn{18}{|l|}{$\operatorname{Var}_{\mathrm{c}}$} \\
\hline $\mathrm{VF}_{\mathrm{no}}$ & $-1.70 \pm 0.37$ & $-2.21 \pm 0.13$ & \multirow{2}{*}{$\begin{array}{l}F(1,31) \\
=.035\end{array}$} & \multirow{2}{*}{.852} & \multirow{2}{*}{.001} & \multirow{2}{*}{$\begin{array}{c}F(1,31) \\
=22.65\end{array}$} & \multirow{2}{*}{$<.001$} & \multirow{2}{*}{.422} & \multirow{2}{*}{$\begin{array}{l}F(1,31) \\
=19.93\end{array}$} & \multirow{2}{*}{$<.001$} & \multirow{2}{*}{391} & $0.02 \pm 0.03$ & 0.489 & 0.631 & $-0.00 \pm 0.00$ & -1.314 & 0.218 \\
\hline $\mathrm{VF}_{\mathrm{rt}}$ & $-1.31 \pm 0.50$ & $-1.86 \pm 0.22$ & & & & & & & & & & $-0.06 \pm 0.04$ & -1.582 & 0.13 & $-0.03 \pm 0.02$ & -1.514 & 0.161 \\
\hline $\mathrm{VF}_{250}$ & $-0.76 \pm 0.66$ & $-1.03 \pm 0.51$ & $\begin{array}{l}F(2,62) \\
=12,61\end{array}$ & $<.001$ & .289 & $\begin{array}{c}F(1,31) \\
=84\end{array}$ & .365 & .026 & $F(2,62)$ & $<.001$ & .769 & $-0.00 \pm 0.05$ & -0.082 & 0.935 & $-0.18 \pm 0.05$ & -3.760 & 0.004 \\
\hline $\mathrm{VF}_{500}$ & $-0.45 \pm 0.57$ & $-0.09 \pm 0.37$ & & & & & & & & & & $0.01 \pm 0.05$ & 0.129 & 0.899 & $-0.08 \pm 0.10$ & -0.766 & 0.464 \\
\hline$A_{\text {norm }}$ & & & & & & & & & & & & & & & & & \\
\hline $\mathrm{VF}_{\mathrm{no}}$ & $0.93 \pm 0.23$ & $0.86 \pm 0.16$ & $F(1,42)$ & 991 & $<001$ & $F(1,42)$ & 218 & 036 & $F(1,42)$ & 009 & 153 & $0.07 \pm 0.05$ & 1.466 & 0.155 & $0.12 \pm 0.04$ & 2.650 & 0.019 \\
\hline $\mathrm{VF}_{\mathrm{rt}}$ & $0.83 \pm 0.20$ & $0.77 \pm 0.16$ & $<.001$ & .991 & $<.001$ & $=1.56$ & .218 & & $=7.60$ & .007 & & $0.04 \pm 0.04$ & 0.974 & 0.34 & $0.12 \pm 0.04$ & 2.639 & 0.019 \\
\hline $\mathrm{VF}_{250}$ & $0.61 \pm 0.19$ & $0.69 \pm 0.21$ & $\begin{array}{c}F(1.45,60.82) \\
=17.64\end{array}$ & $<.001$ & .296 & $\begin{array}{c}F(1,42) \\
=2.35\end{array}$ & .133 & .053 & $\begin{array}{l}F(1.45,60.82) \\
=83.47\end{array}$ & $<.001$ & .665 & $-0.03 \pm 0.03$ & -1.159 & 0.257 & $0.21 \pm 0.06$ & 3.463 & 0.003 \\
\hline $\mathrm{VF}_{500}$ & $0.37 \pm 0.15$ & $0.60 \pm 0.22$ & & & & & & & & & & $-0.03 \pm 0.04$ & -0.715 & 0.481 & $0.20 \pm 0.05$ & 3.828 & 0.002 \\
\hline
\end{tabular}

For $\operatorname{Var}_{c}$ we used 5\%-trimmed datasets (Fig. 3A). The group $\times$ feedback interaction effect was not significant $(p=.606)$. A significant main effect of group indicated greater $\operatorname{Var}_{c}$ for PD patients than for controls $(p<.001)$, while the significant main effect of feedback $(p<.001)$ indicated greater $\operatorname{Var}_{c}$ for $\mathrm{VF}_{\mathrm{rt}}$ than for $\mathrm{VF}_{\text {no }}(p<.001)$.

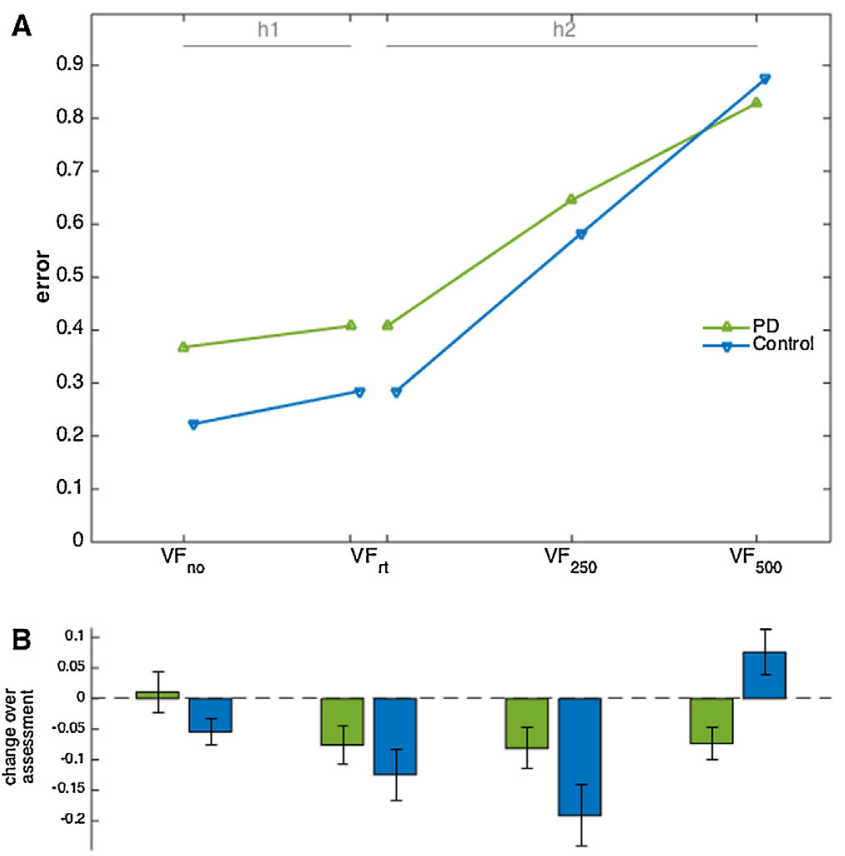

Fig. 2. (A) Error for the group of patients with Parkinson's disease (PD) and the group of control subjects (Control). Note that Error is normalized with respect to the target amplitude and therefore a dimensionless quantity. Mean values are here presented on the original measurement scale; prior to statistical comparison the data were log-transformed (and error bars are therefore omitted). To examine the instantaneous effects of $\mathrm{VF}$ (hypothesis 1) $\mathrm{VF}_{\mathrm{no}}$ and $\mathrm{VF}_{\mathrm{rt}}$ were compared, here represented by the left-hand data $(h 1)$. To examine the reliance on $\mathrm{VF}$ (hypothesis 2 ) we compared $\mathrm{VF}_{\mathrm{rt}}, \mathrm{VF}_{250}$, and $\mathrm{VF}_{500}$, which is depicted by the right-hand data ( $h 2$ ). (B) Change in Error over the course of the assessment. Error bars indicate the standard error.
Comparison of $A_{\text {norm }}$ during $\mathrm{VF}_{\mathrm{no}}$ and $\mathrm{VF}_{\mathrm{rt}}$ revealed a significant main effect of feedback $(p=.009)$, indicating an overall lower $A_{\text {norm }}$ during $\mathrm{VF}_{\mathrm{rt}}$ than during $\mathrm{VF}_{\text {no }}$ (Fig. $4 \mathrm{~A}$ ). Neither the main effect of group $(p=.218)$, nor the interaction effect $(p=.991)$ was significant.

Change scores showed a reduction in Error during $\mathrm{VF}_{\mathrm{no}}$ for the controls $\left(p_{c}=.028\right)$, but not for patients $\left(p_{p}=.752\right.$; see Fig. $\left.2 \mathrm{~B}\right)$. Neither of the groups showed changes in $\operatorname{Var}_{c}\left(p_{p}=.631, p_{c}=.218\right.$;
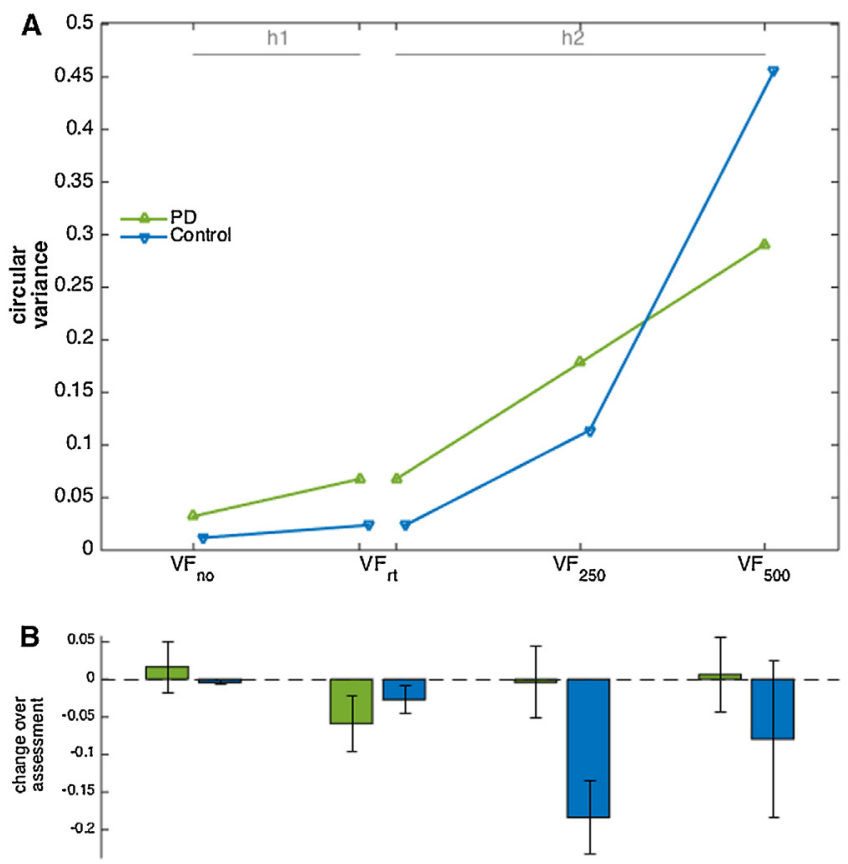

Fig. 3. (A) Circular variance $\left(\operatorname{Var}_{c}\right)$ of the relative phase between target and tracking motion. Note that circular variance is a bounded, dimensionless quantity ranging from 0 to 1 . These data represent the $5 \%$-trimmed means. Mean values are here presented on the original measurement scale; prior to statistical comparison the data were Fisher-transformed (and error bars are therefore omitted). $H 1$ represents the conditions included to test hypothesis $1, h 2$ represents the conditions included to test hypothesis 2. (B) Change in $\operatorname{Var}_{c}$ over the course of the assessment. 

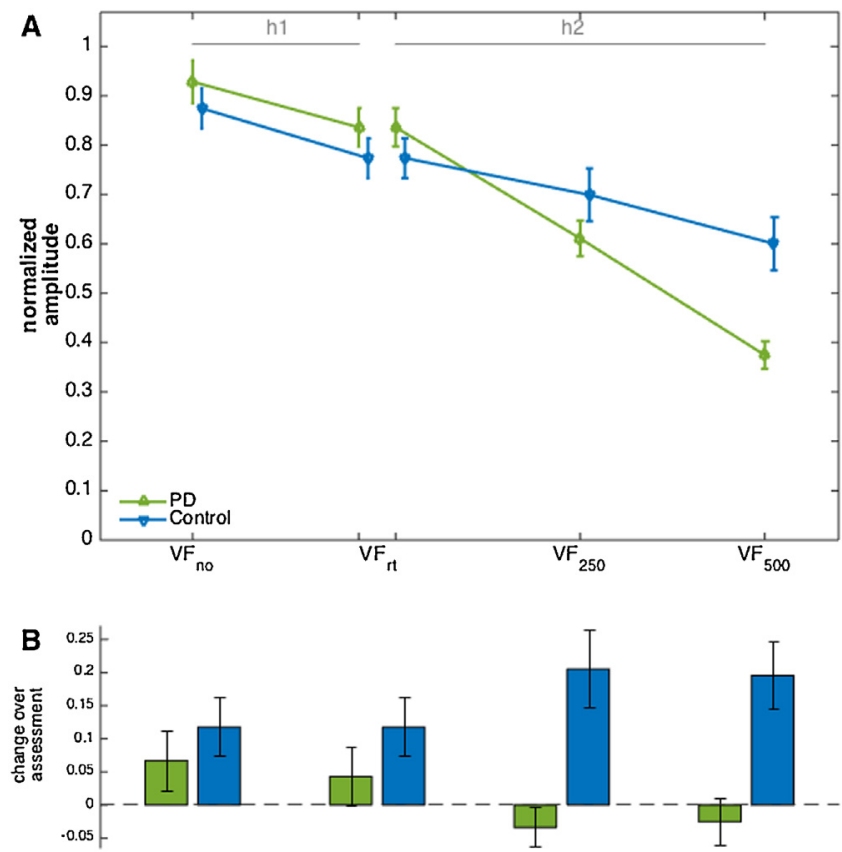

Fig. 4. (A) Normalized amplitude $\left(A_{\text {norm }}\right)$. Note that $A_{\text {norm }}$ is normalized with respect to the target amplitude and therefore a dimensionless quantity. $H 1$ represents the conditions included to test hypothesis $1, h 2$ represents the conditions included to test hypothesis 2. (B) Change in $A_{\text {norm }}$ over the course of the assessment. Error bars indicate the standard error.

see Fig. 3B). $A_{\text {norm }}$ increased significantly for the controls only $\left(p_{p}=.155, p_{c}=.019\right.$; see Fig. $\left.4 \mathrm{~B}\right)$. For $\mathrm{VF}_{\mathrm{rt}}$, both groups showed a reduction in Error $\left(p_{p}=.026, p_{c}=.010\right)$. Neither of the groups showed change in $\operatorname{Var}_{c}\left(p_{p}=.130, p_{c}=.161\right)$, while $A_{\text {norm }}$ again increased significantly only for controls $\left(p_{p}=.340, p_{c}=.019\right)$.

\section{Hypothesis 2. Effects of delay}

Due to a significant Mauchly's test of sphericity for Error and $\operatorname{Var}_{c}$ we report Huynh-Feldt-corrected values for those outcomes (Table 1). A significant group $\times$ delay interaction was found for Error ( $p=.006$; see Fig. 2A), for $\operatorname{Var}_{c}(p<.001$, see Fig. 3A) and for $A_{\text {norm }}(p<.001$; see Fig. $4 \mathrm{~A})$.

Change scores during $\mathrm{VF}_{250}$ showed improvements in Error in both groups ( $p_{p}=024, p_{c}=.002$; see Fig. 2B). The decrease in $\operatorname{Var}_{c}$ $\left(p_{p}=935, p_{c}=004\right.$; see Fig. $\left.3 \mathrm{~B}\right)$ and the increase in $A_{\text {norm }}\left(p_{p}=257\right.$, $p_{c}=004$; see Fig. $4 \mathrm{~B}$ ) were significantly for the control group only. During $\mathrm{VF}_{500}$ the reduction in Error in the PD group was significant $\left(p_{p}=012\right)$, while the increase for controls was not $\left(p_{c}=059\right)$. There were no significant changes in $\operatorname{Var}_{c}\left(p_{p}=899, p_{c}=.464\right)$, while $A_{\text {norm }}$ increased significantly for the control group only $\left(p_{p}=482\right.$, $p_{c}=.002$ ).

\section{Discussion}

Subjects with PD performed lateral swaying motions with greater error and more variable movement patterns than controls, both during the condition without feedback and during the condition with real-time feedback. These findings suggest that the task differentiated between these two groups, thereby supporting suggestions that postural control in patients with PD is notably affected along the ML axis (e.g., $[3,4])$. The results further showed that over the course of the experiment, instantaneous VF helped both groups in better coordinating their motion with that of the target, thereby confirming our first hypothesis and supporting findings from other studies (cf. [27]).
With incongruent feedback, the task became more progressively more difficult (Fig. 2A). However, with $V^{250}$, control subjects were able to decrease the error over the course of the experiment, paired with a marked decrease in variability and an increase in amplitude. This suggests that - although challenging at first - these subjects were able to adapt to delays of $250 \mathrm{~ms}$ over time. However, for patients with PD we observe smaller improvements in Error, and little improvements in the heightened variability. This suggests that a stable sensorimotor mapping was not achieved. Furthermore, this group performed this condition with significantly reduced $A_{\text {norm }}$ (which will be at least partially responsible for the reduction in Error $^{1}$ ).

The condition with 500 ms delays was characterized by high Error and high $\operatorname{Var}_{c}$, both of which did not improve over the course of the assessment, suggesting this condition was too challenging to adapt to in a stable fashion. Although the patient group improved in Error, this was likely again the result of the strongly reduced movement amplitude.

We conclude that patients with PD can indeed learn to improve postural movement coordination with VF, albeit to a lesser extent than healthy controls. Crucially, whereas controls seem to be able to adapt to a certain amount of visual incongruity $\left(\mathrm{VF}_{250}\right)$, patients with PD were not able to do so. Instead, movement amplitude was significantly reduced in this group. Though this in part helps to stave off increases in Error, the movement amplitude is also a primary component of performance in many tasks, and this strategy can hence be considered unfavorable. Decreased movement amplitude in response to delays have been previously reported for individuals with PD [10]. It may reflect a 'conservative' strategy that - even though it precludes optimal performance - minimizes the risk of complete performance breakdown. All in all, the results confirm our hypothesis that patients with PD are affected more by incongruent VF than healthy controls, which is also in line with other studies [28].

Recognizing the adverse effects of unreliable VF in this patient group is especially relevant as rehabilitation with virtual reality techniques is becoming more widely available. Factors that limit the extent to which patients are able to effectively use VF will likely limit the efficacy of such therapies [27]. Patients with PD might require more extensive practice before real-time VF is beneficial to performance.

The value of VF does not only seem to depend on the type of feedback and the way in which it is provided, it may also be taskspecific. We employed a technologically straightforward, nonimmersive VF setup with a limited number of experimental conditions. The PD group was relatively heterogeneous and some effects might have been weakened by this mixed group composition. Unfortunately, the included number of subjects did not allow for subgroup analyses. Our results should be interpreted in light of such limiting factors. Despite these limitations the here-employed VF revealed significant differences in postural control between PD patients and age- and gendermatched controls. However, further evaluation of the general efficacy of VF in PD will require more elaborate study designs (including training) in future studies.

\section{Conflicts of interest}

All authors declare no conflict of interest.

\footnotetext{
${ }^{1}$ The optimal amplitude, i.e. the amplitude that minimizes Error, depends on the phase difference between target and COP: it ranges from target amplitude size for zero phase difference to an amplitude of zero for phase differences between approximately $(1 / 2) \pi$ and $(3 / 2) \pi$.
} 


\section{Acknowledgements}

The authors are grateful to Ingrid Burgers and Cees de Goede for recruiting the patients and to Bert Clairbois and Bert Coolen for their technical support. The authors acknowledge the assistance of Floris Booij, Valerie Gollnhofer, Malik Megharia, Peter Kaagman, Martijn Kool, and Joshua Renders during the measurements. This study was made possible through a grant of the Stichting Parkinson Fonds awarded to EvW and GK.

\section{Appendix A. Supplementary data}

Supplementary data associated with this article can be found, in the online version, at http://dx.doi.org/10.1016/j.gaitpost.2016.03. 020 .

\section{References}

[1] Jankovic J. Parkinson's disease: clinical features and, diagnosis. J. Neurol. Neurosurg. Psychiatry 2008;79:368-76. http://dx.doi.org/10.1136/innp.2007.131045.

[2] Winter DA. A.B.C. (Anatomy, Biomechanics and Control) of Balance during Standing and Walking. Waterloo Biomechanics; 1995.

[3] Mancini M, Carlson-Kuhta P, Zampieri C, Nutt JG, Chiari L, Horak FB. Postural sway as a marker of progression in Parkinson's disease: a pilot longitudinal study. Gait Posture 2012;36:471-6.

[4] van Wegen EEH, van Emmerik REA, Wagenaar RC, Ellis T. Stability boundaries and lateral postural control in Parkinson's disease. Motor Control 2001:5:254.

[5] Nieuwboer A, Kwakkel G, Rochester L, Jones D, van Wegen EEH, Willems AM, et al. Cueing training in the home improves gait-related mobility in Parkinson's disease: the RESCUE trial. J. Neurol. Neurosurg. Psychiatry 2007;78:134.

[6] Spaulding SJ, Barber B, Colby M, Cormack B, Mick T, Jenkins ME. Cueing and gait improvement among people with Parkinson's disease: a meta-analysis. Arch. Phys. Med. Rehabil. 2013;94:562-70. http://dx.doi.org/10.1016/ j.apmr.2012.10.026.

[7] van Wegen EEH, Hirsch MA, Huiskamp M, Kwakkel G. Harnessing cueing training for neuroplasticity in Parkinson disease. Top. Geriatr. Rehabil. 2014;30:46-57. http://dx.doi.org/10.1097/TGR.0000000000000005.

[8] Azulay JP, Mesure S, Amblard B, Pouget J. Increased visual dependence in Parkinson's disease. Percept. Mot. Skills 2002;95:1106-14.

[9] Bronstein AM, Hood JD, Gresty MA, Panagi C. Visual control of balance in cerebellar and parkinsonian syndromes. Brain 1990;113:767.

[10] Beuter A, Milton JG, Labrie C, Glass L, Gauthier S. Delayed visual feedback and movement control in Parkinson's disease. Exp. Neurol. 1990;110:228-35. http://dx.doi.org/10.1016/0014-4886(90)90034-P.

[11] van den Heuvel MRC, Balasubramaniam R, Daffertshofer A, Longtin A Beek PJ. Delayed visual feedback reveals distinct time scales in balance control. Neurosci. Lett. 2009;452:37-41. http://dx.doi.org/10.1016/j.neulet.2009.01.024.
[12] Yeh TT, Cluff T, Balasubramaniam R. Visual reliance for balance control in older adults persists when visual information is disrupted by artificial feedback delays. PLOS ONE 2014;9:e91554. http://dx.doi.org/10.1371/journal.pone.0091554.

[13] Miall RC, Weir DJ, Stein JF. Visuomotor tracking with delayed visual feedback. Neuroscience 1985;16:511-20.

[14] van den Heuvel MRC, van Wegen EEH, de Goede CJT, Burgers-Bots IAL, Beek PJ, Daffertshofer A, et al. The effects of augmented visual feedback during balance training in Parkinson's disease: study design of a randomized clinical trial. BMC Neurol. 2013;13:137.

[15] van den Heuvel MRC, Kwakkel G, Beek PJ, Berendse HW, Daffertshofer A, van Wegen EEH. Effects of augmented visual feedback during balance training in Parkinson's disease: a pilot randomized clinical trial. Parkinsonism Relat. Disord. 2014;20:1352-8. http://dx.doi.org/10.1016/j.parkreldis.2014.09.022.

[16] Gibb WR, Lees AJ. The relevance of the Lewy body to the pathogenesis of idiopathic Parkinson's disease. J. Neurol. Neurosurg. Psychiatry 1988;51:74552. http://dx.doi.org/10.1136/jnnp.51.6.745.

[17] Duncan PW, Weiner DK, Chandler J, Studenski S. Functional reach: a new clinical measure of balance. J. Gerontol. 1990;45. http://dx.doi.org/10.1093/ geronj/45.6.M192. M192-7.

[18] Berg KO, Wood-Dauphinee SL, Williams JI, Maki B. Measuring balance in the elderly: validation of an instrument. Can. J. Public Health 1992;83(Suppl. 2). S7-11.

[19] Steffen T, Seney M. Test-retest reliability and minimal detectable change on balance and ambulation tests, the 36-item short-form health survey, and the unified Parkinson disease rating scale in people with parkinsonism. Phys. Ther. 2008;88:733-6. http://dx.doi.org/10.2522/ptj.20070214.

[20] Tinetti ME, Richman D, Powell L. Falls efficacy as a measure of fear of falling. J. Gerontol. 1990;45:239-43. http://dx.doi.org/10.1093/geronj/45.6.P239.

[21] Zigmond AS, Snaith RP. The hospital anxiety and depression scale. Acta Psychiatr. Scand. 1983;67:361-70.

[22] Elbers RG, van Wegen EEH, Verhoef J, Kwakkel G. Reliability and structural validity of the Multidimensional Fatigue Inventory (MFI) in patients with idiopathic Parkinson's disease. Parkinsonism Relat. Disord. 2012;18:532-6. http://dx.doi.org/10.1016/j.parkreldis.2012.01.024.

[23] Smets EMA, Garssen B, Bonke B, de Haes JCJM. The multidimensional Fatigue Inventory (MFI) psychometric qualities of an instrument to assess fatigue. J. Psychosom. Res. 1995;39:315-25. http://dx.doi.org/10.1016/ 0022-3999(94)00125-O.

[24] Fitzpatrick R, Peto V, Jenkinson C, Greenhall R, Hyman N. Health-related quality of life in Parkinson's disease: a study of outpatient clinic attenders. Mov. Disord. 1997;12:916-22. http://dx.doi.org/10.1002/mds.870120613.

[25] van Wegen EEH, Lim LIIK, Nieuwboer A, Willems AM, De Goede CJT, BurgersBots IAL et al. Klinimetrie bij de ziekte van Parkinson: een praktische handleiding. Amersfoort: Nederlands Paramedisch Instituut; VU medisch centrum; 2005.

[26] Mardia KV, Jupp PE. Directional Statistics. Chichester: Wiley; 2000.

[27] Nieuwboer A, Rochester L, Müncks L, Swinnen SP. Motor learning in Parkinson's disease: limitations and potential for rehabilitation. Parkinsonism Relat. Disord. 2009;15:S53-8. http://dx.doi.org/10.1016/S13538020(09)70781-3.

[28] De Nunzio AM, Nardone A, Schieppati M. The control of equilibrium in Parkinson's disease patients: delayed adaptation of balancing strategy to shifts in sensory set during a dynamic task. Brain Res. Bull. 2007;74:25870. http://dx.doi.org/10.1016/j.brainresbull.2007.06.020. 